\title{
Non-traded goods, the trade balance, and the balance of payments
}

\author{
JEREMY GREEN W OOD / University of Western Ontario
}

\begin{abstract}
A small-scale general equilibrium model is constructed to explain the joint behaviour of the trade balance, balance of payments, relative price of non-traded goods, and the real exchange rate. The model can be used to obtain a set of predictions about the response of these four variables to various exogenous disturbances, such as movements in the terms of trade or changes in government expenditure. The analysis emphasizes the interconnectedness between the traded and non-traded goods sectors of an economy. Since different exogenous shocks imply different patterns of co-movement between the trade balance, balance of payments, relative price of nontraded goods, and the real exchange rate, the general relationship between movements in these variables is theoretically ambiguous.
\end{abstract}

Biens non-transigés internationalement, balance commerciale et balance des paiements. L'auteur construit un modèle d'équilibre général de petite taille pour expliquer conjointement le comportement de la balance commerciale, de la balance des paiements, du prix relatif des biens non-transigés internationalement et du taux de change réel. On peut utiliser le modèle pour obtenir des prédictions quant à la réaction de ces quatre variables à divers chocs exogènes comme des mouvements dans les termes d'échange ou des changements dans le niveau des dépenses gouvernementales. L'analyse met l'accent sur l'interconnexion entre le secteur des biens transigés internationalement et le secteur des biens non-transigés d'une économie. Puisque divers chocs exogènes vont engendrer des patterns différents de réaction conjointe de ces quatre variables, la nature de la relation entre les mouvements dans ces variables est théoriquement ambiguë.

\section{N T R O D U C T I O N}

Several recent papers in international finance have analysed the joint determination of a nation's exchange rate and trade balance within the construct of small-scale choice-theoretic intertemporal general equilibrium models. For instance, Sachs (1983) and Greenwood (1983a) use these models to obtain a set of predictions about the pattern of co-movement between the exchange rate and the trade balance conditional upon knowledge about movements in certain key economic variables such as real income, government spending, and the money supply. The unconditional correlation between changes in the trade balance and the exchange rate turns out to be

I would like to thank Ian Wooton for helpful comments and suggestions. 
ambiguous. This is because the association between movements in these two variables depends in an essential manner on the specific nature of exogenous disturbances impinging on certain key economic variables, such as those mentioned above.

This paper extends the above line of research by introducing non-traded goods into the analysis. An examination is undertaken of the co-determination of the trade balance, the balance of payments, the relative price of non-traded goods, and the real exchange rate in a small open economy with a fixed exchange rate. Disturbances originating within the non-traded goods market have important implications for both the trade balance and the balance of payments that have not been fully recognized before. Also, shocks emanating from outside the nontraded goods sector now have an additional channel of effect on the open sector of the economy owing to their impact on the relative price of non-traded goods. Furthermore, the inclusion of non-traded goods in international finance models is essential if movements in the real exchange rate are to be analysed in a meaningful manner. An appealing feature of the mode of analysis adopted in this paper is that it allows the main results to be cast in terms of familiar income and substitution effects that highlight the main factors that come into play. In this respect, the line of argument employed here parallels that utilized in Jones's (1974) earlier study on trade with non-traded goods. It should also be mentioned that some of the issues dealt with arise naturally in Stockman's (1983) analysis of the real effects of alternative nominal exchange rate systems. ${ }^{1}$

Finally, a word on the choice of modelling strategy adopted here. A fundamental property of choice-theoretic intertemporal general equilibrium models is that agents' decision-making is undertaken in a rational manner, based upon forward-looking expectations about real income, real rates of return, government spending, and money supplies. By adopting such an approach, it is hoped that agents' decision rules will be well grounded in economic theory. In some cases such an approach has led to considerable doubt's being cast upon some orthodox views in international finance. For example, Helpman (1981), Lucas (1982), and Stockman (1983) all challenge the traditional belief that fixed and flexible exchange rate systems have fundamentally differing effects on real allocations within an economy. ${ }^{2}$ Obstfeld (1982) and Stockman (1983) arrive at the conclusion that the scope for sterilized interventions in the foreign exchange market is severely limited - perhaps even non-existent. ${ }^{3}$ Also, these models have been able to explain so-called empirical anomalies. For instance, Stockman (1980) gives an equilibrium explanation of the long-observed correlation between the nominal and real exchange rates - a fact that many claimed conclusively proved price rigidity in the goods market. A theoretical justification for the lack of an observed correlation between the trade balance and the exchange rate across countries and time periods is provided by Sachs (1983) and Greenwood (1983a).

1 Kimbrough (1983), in his examination of the effects of government purchases in an open economy, also addresses some of these issues within the context of a reduced-form macro-economic model based on a variant of the Lucas-Barro supply function.

2 On this topic see also Aschauer and Greenwood (1983) and Stockman (1981).

3 For a discussion of some related issues, see also Persson (1984). 


\section{THE MODEL'S SETTING}

Imagine a small open economy, with a lifespan of two periods, that has adopted a system of fixed exchange rates. This economy is inhabited by a representative agent who is blessed with perfect foresight, and who desires to maximize his lifetime utility, $\underline{U}(\cdot)$, as given by

$$
\underline{U}(\cdot)=\sum_{t=1}^{2} \beta^{t-1} U\left(N^{t}, Z^{t}\right),
$$

where $\beta$ is his subjective discount factor, and $N^{t}$ and $Z^{t}$ are his consumption of a non-traded and an imported good, respectively, in period $t$. The momentary utility function, $U(\cdot)$, is assumed to be strictly quasi-concave and twice differentiable with both non-tradeables and imports being normal goods.

In each period $t$ the representative agent is endowed with a certain quantity of the non-traded good, $\bar{N}^{t}$, and an exported good, $\bar{X}^{t}$. Non-traded goods sell within the domestic economy during period $t$ at a relative price in terms of imports of $p_{N}{ }^{t}$. Also, during this period the export good may be freely sold to the rest of the world at the world terms of trade, $p_{X}{ }^{t}$, by which is meant the relative price of exports in terms of imports. Thus, when measured in terms of the imported good, the individual's real income, $y^{t}$, would be equal to $p_{N}{ }^{t} \bar{N}^{t}+p_{X}{ }^{t} \bar{X}^{t}$.

Domestic residents can also freely participate on an international bond market. In the first period the representative agent can purchase or sell real bonds, which are denominated in terms of the imported good and pay the fixed internationally determined real rate of return, $r^{*}$. For instance, if during the first period the agent purchased one unit of real bonds, he would receive the equivalent of $1+r^{*}$ units of the imported good during period two.

Now, the individual may choose to hold domestic currency so as to economize on his transactions costs of exchange. Specifically, in each period the fraction $v$ of the agent's real income, $y$, is absorbed in transactions costs. This fraction $v$ is assumed to be a decreasing convex function of the ratio of the agent's nominal money balances, $M$, to his nominal income, $P y$, where $P$ is the nominal price of the imported good. Thus, for a given level of nominal income, there are diminishing returns to holding money. By increasing his holdings of money, the individual can economize on the proportion of his real income that is being absorbed in transactions costs. However, as the ratio of money, $M$, to nominal income, $P y$, rises, the reduction in the fraction, $v$, of real income brought about by holding an extra unit of money is reduced. In other words,

$$
v^{t}=v\left(M^{t} / P^{t} y^{t}\right) \quad \forall_{t}=1,2 \text { with } v^{\prime}<0 ; v^{\prime \prime}>0 \text {; and } 0<v<1 .
$$

Lastly, there is a government in this 'small' open economy. In each period the government undertakes a certain amount of unproductive expenditure. In particular, during $t$ the government purchases the quantities $g_{N}{ }^{t}$ of the non-traded good and $g_{Z}{ }^{t}$ of the imported good. Therefore, the total value of real government spending on goods 
during period $t$ when measured in terms of the imported good, or $g^{t}$, would be

$$
g^{t}=p_{N}{ }^{t} g_{N}{ }^{t}+g_{Z}{ }^{t}
$$

Also, during period $t$ the government gives the individual a real transfer payment in the amount $\mu^{t}$ and taxes him $\tau^{t}$. These transfer payments and taxes are unrelated to the agent's holdings of real balances.

Like any other actor in the economy, the government must satisfy a budget constraint in each period. Its budget constraints for the two periods are

$$
M_{s}{ }^{1} / P^{1}=g^{1}+\mu^{1}+b^{1}-\tau^{1}
$$

and

$$
\left(M_{s}^{2}-M_{s}{ }^{1}\right) / P^{2}=g^{2}+\mu^{2}-\left(1+r^{*}\right) b^{1}-\tau^{2},
$$

where $M_{s}{ }^{1}$ and $M_{s}{ }^{2}$ are the stocks of domestic currency in periods one and two, and $b^{1}$ is the quantity (which may be negative) of the import denominated real bond that the government purchases from the rest of the world. For simplicity, it will be assumed that the government uses current taxation to meet its current expenditure on goods. That is, let $g^{t}=\tau^{t}$. The variable $b^{1}$ can now be regarded as the balance of payments in the first period.

THE INDIVIDUAL'S MAXIMIZATION PROBLEM

The representative agent's constrained maximization problem is shown below, the agent's decision variables being $N^{1}, N^{2}, Z^{1}, Z^{2}, M^{1} / P^{1}$, and $M^{2} / P^{2}$.

$$
\begin{array}{ll}
\operatorname{Max} & U\left(N^{1}, Z^{1}\right)+\beta U\left(N^{2}, Z^{2}\right) \\
\text { s.t. } & p_{N}{ }^{1} N^{1}+Z^{1}+M^{1} / P^{1}+\left[1 /\left(1+r^{*}\right)\right]\left[p_{N}{ }^{2} N^{2}+Z^{2}+\left(M^{2}-M^{1}\right) / P^{2}\right] \\
& =\left[1-v\left(M^{1} / P^{1} y^{1}\right)\right] y^{1}+\mu^{1}-\tau^{1}+\left[1 /\left(1+r^{*}\right)\right]\left\{\left[1-v\left(M^{2} / P^{2} y^{2}\right)\right] y^{2}+\mu^{2}\right. \\
& \left.-\tau^{2}\right\} .
\end{array}
$$

The above optimization problem implies that if the individual is to hold real balances efficiently in the first period the following condition must hold:

$$
-v^{\prime}\left(M^{1} / P^{1} y^{1}\right)=\left(\pi+r^{*}\right) /\left(1+r^{*}\right),
$$

where $\pi \equiv\left(P^{2}-P^{1}\right) / P^{2}$. The left-hand side of the above expression represents the marginal product of a unit of real balances in the first period. The right-hand side of this expression is the opportunity cost of holding a unit of real balances in the first period. Obviously, the efficient utilization of money requires the marginal product of the last unit of real balances held to equal its marginal cost. By inverting the above equation, a standard-looking demand for money function for the agent can be derived 


$$
\begin{array}{r}
M^{1} / P^{1}=k^{1}\left(\left(\pi+r^{*}\right) /\left(1+r^{*}\right)\right) y^{1} \quad k^{1}(\cdot) \equiv v^{\prime-1}\left(-\left(\pi+r^{*}\right) /\left(1+r^{*}\right)\right) \\
k^{1 \prime}<0
\end{array}
$$

This equation will be useful in analyzing the impact of various shocks on the balance of payments.

The agent's optimization problem implies that his compensated demand functions for non-traded and imported goods will take the following forms

$$
\begin{aligned}
& N^{1}=N^{1}\left(p_{N}^{1}, p_{N}^{2} /\left(1+r^{*}\right), \begin{array}{c}
1 /\left(1+r^{*}\right), \underset{+}{\omega}+ \\
+
\end{array}\right. \\
& N^{2}=N^{2}\left(p_{N}{ }^{1}, p_{N}{ }^{2} /\left(1+r^{*}\right), \underset{+}{\left.1 /\left(1+r^{*}\right), \omega\right)}\right. \\
& Z^{1}=\underset{?}{Z^{1}\left(p_{N}{ }^{1}, p_{N}{ }^{2} /\left(1+r^{*}\right), 1 /\left(1+r^{*}\right), \omega\right)}+\underset{+}{\omega}+ \\
& Z^{2}=\underset{+}{Z^{2}\left(p_{N}{ }^{1}, p_{N}{ }^{2} /\left(1+r^{*}\right), 1 /\left(1+r^{*}\right), \omega\right)}
\end{aligned}
$$

where $\omega$ is an index of his real welfare level. The sign under an argument in one of these demand functions shows the sign, implied by the consumer's problem (3), of the partial derivative of that demand function with respect to the argument in question. ${ }^{4}$ Needless to say, the actor's level of real welfare, $\omega$, is dependent on factors such as his endowments of non-traded and exported goods, the relative prices of non-traded and exported goods, the levels of real taxes and transfer payments, and the rates of return on holding money, $-\pi$, and bonds, $r^{*}$. The nature of this dependence is discussed in fuller detail later.

The structure of the agent's optimization problem implies that his demand for money decision influences his consumption of the non-traded and imported goods each period only through an income effect brought about by a reduction in the individual's transactions costs of exchange (net of the cost of holding money) due to the fact that he holds money. Consequently, $\pi$ does not appear directly in the above compensated demand functions. The influence of $\pi$ on the various good's consumption is felt indirectly through $\omega$. As the rate of return on holding money, $-\pi$, changes, the individual adjusts his holdings of real balances. This leads to movements in (net) transactions costs which have income effects that cause $\omega$ to shift. ${ }^{5}$

\section{THE MODEL'S GENERAL E Q U ILIBR I U M}

In the model's general equilibrium the money market must always clear. Consequently,

4 If the momentary utility function was separable in non-traded and imported goods, then the question marks under the various arguments in these demand functions could be replaced by plus signs.

5 See Greenwood (1983b, appendix A) for further details. 


$$
M^{t}=M_{s}^{t} \quad t=1,2 .
$$

Also, the non-traded goods market must clear domestically each period, implying that

$$
N^{t}=\left(1-v\left(M^{t} / P^{t} y^{t}\right)\right) \bar{N}^{t}-g_{N}^{t} \quad t=1,2 .
$$

The left-hand side of the above equation shows the demand for non-traded goods by the representative agent in period $t$. The right-hand side shows the net supply of non-traded goods available to private citizens in that period. This is equal to the total supply of non-traded goods minus that portion of this supply which is absorbed in the transactions costs of exchange and less the amount of non-traded goods which is purchased by government.

An economy-wide budget constraint may be obtained by substituting the government's budget constraints (1) and (2) into the individual's one. This yields

$$
\begin{gathered}
p_{N}{ }^{1} N^{1}+Z^{1}+g^{1}+\left[1 /\left(1+r^{*}\right)\right]\left[p_{N}^{2} N^{2}+Z^{2}+g^{2}\right]=\left[1-v\left(M^{1} / P^{1} y^{1}\right)\right] y^{1} \\
+\left[1 /\left(1+r^{*}\right)\right]\left[1-v\left(M^{2} / P^{2} y^{2}\right)\right] y^{2}
\end{gathered}
$$

By imposing equilibrium in the non-traded goods market, the above economy-wide budget constraint can be rewritten to obtain the following relationship, which states that trade must balance intertemporally:

$$
\begin{aligned}
& t^{1} \equiv\left\{\left[1-v\left(M^{1} / P^{1} y^{1}\right)\right] p_{X}{ }^{1} \bar{X}^{1}-Z^{1}-g_{Z}{ }^{1}\right\} \\
& \quad=-\left[1 /\left(1+r^{*}\right)\right]\left\{\left[1-v\left(M^{2} / P^{2} y^{2}\right)\right] p_{X}{ }^{2} \bar{X}^{2}-Z^{2}-g_{Z}{ }^{2}\right\} .
\end{aligned}
$$

The term in the brace on the left-hand side of the above equality sign represents the current period's trade balance, $t^{1}$, while the term in the brace on the right-hand side represents the second period's trade balance, $t^{2}$. As can be then seen, $t^{1}=-[1 /(1+$ $\left.\left.r^{*}\right)\right] t^{2}$.

Now, the law of one price states that

$$
P^{t}=\bar{e} P_{F}^{t} \quad t=1,2,
$$

where $\bar{e}$ is the fixed domestic currency price for a unit of foreign currency and $P_{F}{ }^{t}$ is the period- $t$ foreign nominal price of the imported good. The above law and the definition for $\pi$ imply that $\pi=\left(P_{F}^{2}-P_{F}^{1}\right) / P_{F}^{2}$. As can be seen, because this economy is a small open one with a fixed exchange rate, $\bar{e}$, its domestic nominal price of imported goods in both periods, $P^{1}$ and $P^{2}$, and, consequently, the rate of return on holding money, $-\pi$, are exogenous data determined from abroad. Thus, the opportunity cost of holding $\left(\pi+r^{*}\right) /\left(1+r^{*}\right)$ is determined exogenously from outside the economy.

Finally, the government's budget constraint (1) implies that today's balance of payments, $b^{1}$, may be written as

$$
b^{1}=\left(M_{s}^{1} / P^{1}\right)-\mu^{1}
$$


(recall that $g^{t}=\tau^{t} \forall t$ ). However, for this small open economy with a fixed exchange rate, the current supply of money, $M_{s}{ }^{1}$, is an endogenous variable determined by the demand for it, $M^{1}$. Thus, by imposing equilibrium in the money market, or equation (6), one may rewrite the above expression as

$$
b^{1}=\left(M^{1} / P^{1}\right)-\mu^{1}=k^{1}\left(\left(\pi+r^{*}\right) /\left(1+r^{*}\right)\right) y^{1}-\mu^{1}
$$

(by using (4))

\section{COMPARATIVE STATICS EXERCISES}

It is interesting to analyse how movements in the terms of trade or changes in government expenditure impact on the relative price of non-traded goods, the trade balance, and the balance of payments. There are many possible comparative statics exercises that could be undertaken, but only the effect of an anticipated improvement in the future terms of trade and of a temporary increase in current government spending on non-traded goods will be discussed in detail here. The results of some other comparative statics exercises are reported in table 1 at the end of this section.

To begin with, suppose that there is an anticipated improvement in the future terms of trade. In other words, suppose that $\hat{p}_{X}{ }^{2}>0$ while $\hat{p}_{X}{ }^{1}=0$, where the "^, over a variable denotes that its proportionate rate of change is being discussed; for example, $\hat{p}_{X}{ }^{2}=d p_{X}{ }^{2} / p_{X}{ }^{2}$. As a consequence of this beneficial change in the future terms of trade, the representative agent immediately realizes an improvement in his welfare, $\omega$, of the amount

$$
d \omega=\left[1 /\left(1+r^{*}\right)\right](1-v(\cdot 2)) p_{X}{ }^{2} \bar{X}^{2} \hat{p}_{X}^{2},
$$

with $d \omega$ measured in terms of current imports. ${ }^{6,7}$ Thus, the change in the individual's real welfare ensuing from an anticipated change in the future terms of trade is strictly proportional to the discounted value of his net endowment of the exported good in the future period.

This improvement in the actor's real welfare will of course lead, at the original set of relative prices, to increases in his demands for non-traded and imported goods in both periods, a fact that is easily discerned by 'eyeballing' the set of demand functions (5). However, the non-traded goods market must clear domestically and the supply of non-traded goods in each period is fixed. Consequently, the relative prices of nontraded goods in each period, $p_{N}{ }^{1}$ and $p_{N}{ }^{2}$, must adjust so as to maintain equilibrium in the non-traded goods market in face of the gain in the agent's real welfare. The proportionate changes in the relative prices of non-traded goods, $\hat{p}_{N}{ }^{1}$ and $\hat{p}_{N}{ }^{2}$, can be uncovered by subjecting the system of equations (7), describing equilibrium in the non-traded goods market, to the usual comparative statics exercise. The results of this exercise are

\footnotetext{
6 This (perhaps intuitively obvious) proposition is demonstrated formally in Greenwood (1983b), appendix B. The proof follows the well-known one illustrated in Jones (1974).

7 The notation $\cdot t$ within a function is being used to indicate that the arguments of a function are being evaluated at their date $t$ values. Thus, $v(\cdot 2)=v\left(M^{2} / P^{2} y^{2}\right)$.
} 


$$
\begin{aligned}
\hat{p}_{N}{ }^{1} & =\frac{\left[\eta_{2}{ }^{2} m_{N}{ }^{1}\left(p_{X}{ }^{2} \bar{X}^{2} / p_{N}{ }^{1} N^{1}\left(1+r^{*}\right)\right)+\eta_{2}{ }^{1} m_{N}{ }^{2}\left(p_{X}{ }^{2} \bar{X}^{2} / p_{N}{ }^{2} N^{2}\right)\right]}{\Delta} \\
& \equiv A(1-v(\cdot 2)) \hat{p}_{X}{ }^{2}>0
\end{aligned}
$$

and

$$
\begin{aligned}
\hat{p}_{N}{ }^{2} & =\frac{\left[\eta_{1}{ }^{1} m_{N}{ }^{2}\left(p_{X}{ }^{2} \bar{X}^{2} / p_{N}{ }^{2} N^{2}\right)+\eta_{1}{ }^{2} m_{N}{ }^{1}\left(p_{X}{ }^{2} \bar{X}^{2} / p_{N}{ }^{1} N^{1}\left(1+r^{*}\right)\right)\right]}{\Delta} \\
& \equiv B(1-v(\cdot 2)) \hat{p}_{X}{ }^{2}>0
\end{aligned}
$$

with $\Delta \equiv \eta_{1}{ }^{1} \eta_{2}{ }^{2}-\eta_{1}{ }^{2} \eta_{2}{ }^{1}>0$, and where $\eta_{s}{ }^{t}$ is the elasticity-defined to be positive - of the demand function for $t$ th-period non-traded goods with respect to its $s$ th argument and $m_{N}{ }^{t}$ is the marginal propensity to consume th-period non-traded goods. ${ }^{8,9}$

The signs of the above two expressions for $\hat{p}_{N}{ }^{1}$ and $\hat{p}_{N}{ }^{2}$ are both unambiguously positive, as is proved in the appendix. (Since all the terms in the numerators of both expressions are positive, this amounts to saying that the denominator of both expressions, or $\Delta$, is positive, which is in fact the case.) Consequently, an anticipated gain in the future terms of trade leads to an increase in the relative price of non-traded goods in both periods. As has been mentioned, when the future terms of trade improve, the individual feels wealthier, a fact (11) shows. Thus, at the original set of relative prices, the individual will try to increase his consumption of both goods in both periods. However, the supply of non-traded goods is fixed, and this upsurge in the demand for them can only be choked off by a rise in both periods' relative prices for non-traded goods.

A more detailed examination of (12) reveals that the proportionate rise in today's relative price of non-traded goods, or $\hat{p}_{N}{ }^{1}$, is an increasing function of $m_{N}{ }^{1}, m_{N}{ }^{2}, \eta_{2}{ }^{1}$, $\eta_{1}{ }^{2}, p_{X}{ }^{2} \bar{X}^{2} / p_{N}{ }^{1} N^{1}$, and $p_{X}{ }^{2} \bar{X}^{2} / p_{N}{ }^{2} N^{2}$, but a decreasing function of $\eta_{1}{ }^{1}$ and $\eta_{2}{ }^{2} .{ }^{10}$ This can be readily explained intuitively. At the original set of relative prices, when the individual's wealth increases, so does his demand for first-period non-traded goods. This upward shift in demand will be greater the larger is the agent's marginal propensity to consume first-period non-traded goods or the larger is $m_{N}{ }^{1}$. This will cause the relative price of first-period non-traded goods to rise. The extent to which the relative price of first-period non-traded goods rises in response to the upward shift in demand will be governed by the own elasticity of demand for non-traded goods in this period, $\eta_{1}{ }^{1}$. In particular, the larger is this elasticity, or the more willing individuals are to substitute away from the consumption of first-period non-traded

8 For example, $\eta_{1}{ }^{1} \equiv\left(p_{N}{ }^{1} / N^{1}\right)\left(\partial N^{1} / \partial p_{N}{ }^{1}\right)$ and $\eta_{2}{ }^{1} \equiv\left\{\left[p_{N}{ }^{2} /\left(1+r^{*}\right)\right] / N^{1}\right\}\left\{\partial N^{1} / \partial\left[p_{N}{ }^{2} /\left(1+r^{*}\right)\right]\right\}$.

9 In other words, $m_{N}{ }^{1} \equiv p_{N}{ }^{1}\left(\partial N^{1} / \partial \omega\right)$ and $m_{N}{ }^{2} \equiv\left[p_{N}{ }^{2} /\left(1+r^{*}\right)\right]\left(\partial N^{2} / \partial \omega\right)$. Note that the assumption that non-tradables are normal goods implies that both $m_{N}^{1}$ and $m_{N}^{2}$ are positive.

10 These results are obtained by the straightforward differentiation of the solution for $\hat{p}_{N}{ }^{1}$ as given by (12). 
goods in response to an increase in their relative price, the smaller will be the proportionate rise in their price due to a gain in the future terms of trade. The quantity $p_{X}{ }^{2} \bar{X}^{2} / p_{N}{ }^{1} N^{1}$ measures the size of the second-period export market vis-à-vis the first-period non-traded goods market. The bigger this datum is, the bigger will be the upsurge in demand for non-traded goods, owing to the improvement in real welfare relative to the fixed net supply of first-period non-traded goods available to private citizens, and consequently, the larger $\hat{p}_{N}{ }^{1}$ will have to be.

However, the story is not yet over. By applying the reasoning in the above paragraph to the situation prevailing in the second period, one would expect the relative price of second-period non-traded goods, $p_{N}{ }^{2}$, to rise. Specifically, $\hat{p}_{N}{ }^{2}$ on this account should be positively related to $m_{N}^{2}$ and $p_{X}{ }^{2} \bar{X}^{2} / p_{N}{ }^{2} N^{2}$ but inversely related to $\eta_{2}{ }^{2}$. Now, recall that the first-period demand for non-traded goods is positively related to the future relative price of non-traded goods. Therefore, as the relative price for future non-traded goods rises, so does the demand for current non-traded goods. The extent of this increase in demand is regulated by the cross-elasticity of demand for current nontraded goods, $\eta_{2}{ }^{1}$. This increase in demand for current-period non-traded goods leads to an upward movement in their price, $p_{N}{ }^{1}$. This story would lead one to expect that $\hat{p}_{N}{ }^{1}$ should be positively dependent on $\eta_{2}{ }^{1}, m_{N}{ }^{2}$, and $p_{X}{ }^{2} \bar{X}^{2} / p_{N}{ }^{2} N^{2}$ but negatively related to $\eta_{2}{ }^{2}$, as is indeed the case.

Lastly, there is a slight twist to this scenario. Note that when discussing the relative price of future non-traded goods, $p_{N}{ }^{2}$, the role of the relative price of current non-traded goods, $p_{N}{ }^{1}$, in determining the demand for future non-traded goods was omitted. The effect of an increase in $p_{N}{ }^{1}$ on the demand for future non-traded goods and their relative price, $p_{N}{ }^{2}$, depends positively on the cross-elasticity of demand for future non-traded goods, $\eta_{1}{ }^{2}$. But again, a rise in $p_{N}{ }^{2}$ will in turn cause a further rise in $p_{N}{ }^{1}$. Thus, $p_{N}{ }^{1}$ should be positively dependent on $\eta_{1}{ }^{2}$.

Next, an investigation will be undertaken of the impact that an anticipated gain in the future terms of trade has on today's real trade balance, $t^{1}$. Recall that

$$
t^{1}=(1-v(\cdot 1)) p_{X}{ }^{1} \bar{X}^{1}-Z^{1}-g_{Z}{ }^{1},
$$

so that in the situation under analysis ${ }^{11}$

$$
\hat{t}^{1}=-\left\{\xi_{1}{ }^{1} \hat{p}_{N}{ }^{1}+\xi_{2}{ }^{1} \hat{p}_{N}{ }^{2}+m_{Z}{ }^{1}(1-v(\cdot 2))\left[p_{X}{ }^{2} \bar{X}^{2} /\left(1+r^{*}\right)\right] \hat{p}_{X}{ }^{2}\right\}<0,
$$

with $\hat{t}^{1} \equiv d t^{1} / d Z^{1}$, and where $\xi_{1}{ }^{1}$ is the elasticity - whose sign is unknown - of the demand for current imports with respect to the relative price of current non-traded goods, $\xi_{2}{ }^{1}$ is the elasticity - which is positive - of the demand for current imports with respect to the relative price of future non-traded goods, and $m_{Z}{ }^{1}$ is the marginal propensity to consume - again, positive - current imports. The sign of the above expression is unambiguously negative, ${ }^{12}$ a fact that is demonstrated in the appendix.

11 Since the current trade balance, $t^{1}$, may be zero, current imports, $Z^{1}$, instead of $t^{1}$, have been used to deflate $d t^{1}$.

12 As can be deduced from footnote 1 , when the momentary utility function is separable in non-traded and imported goods, $\xi_{1}{ }^{1}$ is positive. Thus, it is then easy to see from (14) that the current trade balance will worsen, or that $\hat{t}^{1}<0$, as a result of the improvement in the future terms of trade. 
Therefore, an anticipated improvement in the future terms of trade causes today's trade balance to worsen.

The above solution for the relative change in the trade balance has intuitive appeal. Once again, the improvement in the agent's welfare due to the anticipated gain in the future terms of trade is $[1-v(\cdot 2)]\left[p_{X}{ }^{2} \bar{X}^{2} /\left(1+r^{*}\right)\right] \hat{p}_{X}{ }^{2}$. Now, the optimizing agent would like to use this increase in his wealth to increase his consumption of both goods in both periods. However, since non-traded goods are fixed in supply, their relative prices must rise in the model's general equilibrium so as to choke off any increased demand for them. Consequently, the increase in the agent's wealth must, in the end, be vented solely on the consumption of imported goods in each period. Since the value of current export production, $[1-v(\cdot 1)] p_{X}{ }^{1} \bar{X}^{1}$, remains constant, an increase in total imports, $Z^{1}+g_{Z}{ }^{1}$, due to an upsurge in private sector import demand results in a movement toward a trade balance deficit today. This trade balance deficit is financed by the private sector borrowing on the international bond market against their higher future export earnings.

Upon a more detailed examination of (14) it can easily be seen there is a greater propensity toward a trade deficit the larger are $\xi_{2}{ }^{1}$ and $m_{Z}{ }^{1}$, ceteris paribus. The bigger $m_{Z}{ }^{1}$ is, the bigger will be the upshift in demand for current imports due to the improvement in real welfare, $[1-v(\cdot 2)]\left[p_{X}{ }^{2} \bar{X}^{2} /\left(1+r^{*}\right)\right] \hat{p}_{X}{ }^{2}$, brought about by the gain in the future terms of trade. Also, the greater $\xi_{2}{ }^{1}$ is, the greater will be the increase in the demand for current imports occurring because of the rise in the relative price of future non-traded goods, $\hat{p}_{N}{ }^{2}$. Finally, since the sign of $\xi_{1}{ }^{1}$ is unknown, nothing can be said about the effect of the rise in the relative price of current non-traded goods, $\hat{p}_{N}{ }^{1}$, on the demand for current imports and, consequently, today's trade balance.

Equation (14) is revealing, because it highlights the fact that shifts in today's trade balance are, in general, related to factors in the non-traded goods market. In a richer model which allowed for the production of both exports and non-tradables to be endogenous, the situations in the traded and non-traded goods markets would be even more intertwined. Here, changes in the relative price of non-traded goods would be associated with shifts in resource allocation between the two sectors. These production effects would have additional ramifications for variables such as the trade balance. For example, in the current case, where the future terms of trade have improved, it seems reasonable to conjecture that the increase in the relative price of current non-traded goods (cf. equation 12) would be linked to a withdrawal of resources from export production and an injection of them into non-traded goods production. This would tend to exacerbate the deteriorating situation in today's trade balance, ceteris paribus.

How does the increase in the future terms of trade affect today's (real) balance of payments? Once again, the balance of payments in the first period, or $b^{1}$, is expressed as

$$
b^{1}=M^{1} / P^{1}-\mu^{1}=k^{1}\left(\left(\pi^{*}+r^{*}\right) /\left(1+r^{*}\right)\right) y^{1}-\mu^{1}
$$


Thus, in the current situation ${ }^{13}$

$$
\begin{aligned}
\hat{b}^{1} & =\hat{y}^{1} & & \text { where } \hat{b}^{1} \equiv d b^{1} /\left(M^{1} / P^{1}\right) \\
& =\left(p_{N}{ }^{1} \bar{N}^{1} / y^{1}\right) \hat{p}_{N}{ }^{1}>0 & & \text { since } \hat{p}_{N}{ }^{1}>0
\end{aligned}
$$

Therefore, an anticipated gain in the future terms of trade causes a balance of payments surplus today. This result occurs because an increase in the future terms of trade leads to the relative price of current non-traded goods rising. This, in turn, causes current real income, $y^{1}$, to increase, leading to an upward shift in current transactions costs of exchange. In order to economize on these increased transactions costs, the agent acquires more real balances, $M^{1} / P^{1}$, which tends to put the balance of payments in surplus.

Next, the impact of a temporary increase in current government spending on non-traded goods on the relative prices of current and future non-traded goods, and today's trade balance, balance of payments, and real exchange rate will be examined. This exercise is interesting, because it focuses on a relationship between the non-traded and traded goods markets that has not been fully recognized before. To begin with, a temporary increase in current government expenditure on non-traded goods would imply that $\hat{g}_{N}{ }^{1}>0$ and $\hat{g}_{N}{ }^{2}=0$. The welfare loss - measured in terms of current import consumption - that individuals would suffer in the face of this event is

$$
d \omega=-p_{N}^{1} g_{N}^{1} \hat{g}_{N}{ }^{1} .
$$

As can be seen, the drop in the agent's real welfare is strictly proportional to the absorption of the supply of current non-traded goods by the government.

Recall that the non-traded goods market must clear domestically each period. Thus, in the current period both the demand and supply of non-traded goods for private citizens has been perturbed. By undertaking the appropriate comparative statics exercise on the system of equations (7) describing equilibrium in the non-traded goods market, one obtains the following results:

$$
\begin{aligned}
\hat{p}_{N}{ }^{1}=-\frac{\left[\eta_{2}{ }^{2} m_{N}{ }^{1}\left(p_{N}{ }^{1} g_{N}{ }^{1} / p_{N}{ }^{1} N^{1}\right)+\eta_{2}{ }^{1} m_{N}{ }^{2}\left(1+r^{*}\right)\left(p_{N}{ }^{1} g_{N}{ }^{1} / p_{N}{ }^{2} N^{2}\right)\right] \hat{g}_{N}{ }^{1}}{\Delta} \\
+\frac{\eta_{2}{ }^{2}\left(p_{N}{ }^{1} g_{N}{ }^{1} / p_{N}{ }^{1} N^{1}\right) \hat{g}_{N}{ }^{1}}{\Delta} \\
=-\left(1+r^{*}\right) A\left(p_{N}{ }^{1} g_{N}{ }^{1} / p_{X}{ }^{2} \bar{X}^{2}\right) \hat{g}_{N}{ }^{1}+\left[\eta_{2}{ }^{2}\left(p_{N}{ }^{1} g_{N}{ }^{1} / p_{N}{ }^{1} N^{1}\right) / \Delta\right] \hat{g}_{N}{ }^{1}>0
\end{aligned}
$$

and

$$
\begin{gathered}
\hat{p}_{N}{ }^{2}=-\frac{\left[\eta_{1}{ }^{1} m_{N}{ }^{2}\left(1+r^{*}\right)\left(p_{N}{ }^{1} g_{N}{ }^{1} / p_{N}{ }^{2} N^{2}\right)+\eta_{1}{ }^{2} m_{N}{ }^{1}\left(p_{N}{ }^{1} g_{N}{ }^{1} / p_{N}{ }^{1} N^{1}\right)\right] \hat{g}_{N}{ }^{1}}{\Delta} \\
+\frac{\eta_{1}{ }^{2}\left(p_{N}{ }^{1} g_{N}{ }^{1} / p_{N}{ }^{1} N^{1}\right) \hat{g}_{N}{ }^{1}}{\Delta} \\
=-\left(1+r^{*}\right) B\left(p_{N}{ }^{1} g_{N}{ }^{1} / p_{X}{ }^{2} \bar{X}^{2}\right) \hat{g}_{N}{ }^{1}+\left[\eta_{1}{ }^{2}\left(p_{N}{ }^{1} g_{N}{ }^{1} / p_{N}{ }^{1} N^{1}\right) / \Delta\right] \hat{g}_{N}{ }^{1} \stackrel{?}{\lesseqgtr} 0
\end{gathered}
$$

13 Since the current balance of payments, $b^{1}$, may be zero, current real balances, $M^{i} / P^{1}$, have been used to deflate $d b^{1}$. 
As can be seen, when current government expenditure on non-traded goods temporarily rises, so does today's relative price of non-traded goods, $p_{N}{ }^{1}$. (The sign of the above expression for $\hat{p}_{N}{ }^{1}$ is proven in the appendix.) The first part of the expression for $\hat{p}_{N}{ }^{1}$, which is familiar from before, shows the negative impact on the relative price for current non-traded goods brought about by a reduction in the demand for them caused by the deterioration in the individual's welfare. This deterioration in the individual's real welfare results from the increased government expenditure on current non-traded goods. The second part of the expression illustrates the positive effect on the relative price of current non-traded goods that a contraction in the net supply of them available to private citizens has. It turns out that this second effect dominates, so that the relative price of current non-traded goods rises, as was probably expected a priori. ${ }^{14}$

Perhaps somewhat surprisingly, a temporary increase in current government spending has an ambiguous impact on the relative price of future non-traded goods. The first term in the expression for $\hat{p}_{N}{ }^{2}$ shows the depressing effect on the relative price of future non-traded goods of a reduction in demand for them, caused by the welfare loss generated by the increased government expenditure. Again, this effect is familiar. The second term shows the positive impact of a reduction in the net supply of current non-traded goods on the relative price of future non-traded goods. This effect is perhaps somewhat subtle. It is operational because, as mentioned, a drop in the net supply of current non-traded goods available to private citizens increases the price for them. However, this increase in the relative price for current non-traded goods leads to individuals' substituting away from the consumption of current non-traded goods to consuming future non-traded goods - and future imports as well. This has a positive impact on the relative price of future non-traded goods. As can be seen, this effect is larger the bigger $\eta_{1}^{2}$ is, which represents the elasticity of demand of future non-traded goods with respect to the relative price of current non-traded goods. The net impact of these two effects is theoretically ambiguous.

However, something more can be said about the sign of the expression for $\hat{p}_{N}{ }^{2}$. In particular, it can be shown (see appendix) that the sign of this expression depends positively on the sign of $U_{12}\left(N^{1}, Z^{1}\right)$. Whether $U_{12}\left(N^{1}, Z^{1}\right)$ is positive or negative determines whether first-period non-traded or imported goods are complements or substitutes, in the (non-standard) Edgeworth-Pareto sense, in the momentary utility function. Now, for example, when $U_{12}\left(N^{1}, Z^{1}\right)$ is negative the initial effect of a reduction in the current net supply of non-traded goods available to the representative agent is to increase the marginal utility of current imports. This leads the agent to desire to consume more current imports. However, to do this, the agent must withdraw expenditure from the second period. Provided that future non-traded goods are normal goods - which was assumed - this leads to a reduction in the demand for them. Given the fixed supply of future non-traded goods, their relative price must thus fall.

14 Simple differentiation of (15) shows that, in the case under discussion, $\hat{p}_{N}{ }^{1}$ is negatively related to $\eta_{1}{ }^{1}, m_{N}{ }^{1}, m_{N}{ }^{2}$, and $\left(p_{N}{ }^{1} g_{N}{ }^{1} / p_{N}{ }^{2} N^{2}\right)$, but positively associated with $\eta_{1}{ }^{2}$ and $\left(p_{N}{ }^{1} g_{N}{ }^{1} / p_{N}{ }^{1} N^{1}\right)$. The effect of $\eta_{2}{ }^{2}$ and $\eta_{2}{ }^{1}$ on $\hat{p}_{N}{ }^{1}$ is ambiguous. More specifically, whether or not $\hat{p}_{N}{ }^{1}$ depends positively or negatively on $\eta_{2}{ }^{2}$ and $\eta_{2}{ }^{1}$ depends on the sign of expression (16) for $\hat{p}_{N}{ }^{2}$. 
Next, the impact that a temporary increase in current government expenditure on non-traded goods has on today's trade balance will be analysed. Expressing the trade balance equation (9) in terms of proportional rates of change yields in this situation that

$$
\hat{t}^{1}=-\xi_{1}{ }^{1} \hat{p}_{N}{ }^{1}-\xi_{2}^{2} \hat{p}_{N}^{2}+m_{N}{ }^{1}\left(p_{N}{ }^{1} g_{N}{ }^{1} / Z^{1}\right) \hat{g}_{N}{ }^{1} \stackrel{?}{\gtrless} 0 .
$$

Unfortunately, the sign of the above expression is theoretically ambiguous. It can be shown, however, that the sign of this expression depends positively on the sign of $U_{12}\left(N^{1}, Z^{1}\right)$ - see appendix. Again, whether $U_{12}\left(N^{1}, Z^{1}\right)$ is positive or negative in turn depends upon whether current non-traded and imported goods are complements or substitutes with each other, in the Edgeworth-Pareto sense, in the momentary utility function. That the change in the trade balance should depend positively on the sign of $U_{12}\left(N^{1}, Z^{1}\right)$ makes intuitive sense. Once again, suppose that $U_{12}\left(N^{1}, Z^{1}\right)$ is negative. Here, a decrease in the supply of current non-traded goods available to private citizens will initially increase the marginal utility of current imported goods. This leads to an upsurge in the demand for current imported goods and a consequent deterioration in the trade balance.

An improvement in the balance of payments occurs in response to the temporary increase in current government spending on non-traded goods. This is because such a change in government spending leads to a rise in the relative price of current non-traded goods, $p_{N}{ }^{1}$, which in turn causes current real income, $y^{1}$, to increase, and consequently the demand for real balances, $M^{1} / P^{1}$, to rise. Algebraically, the expression one gets for the relative change in the balance of payments is

$$
\begin{aligned}
\hat{b}^{1} & =\hat{y}^{1} \\
& =\left(p_{N}{ }^{1} \bar{N}^{1} / y^{1}\right) \hat{p}_{N}{ }^{1}>0
\end{aligned}
$$

since $\hat{p}_{N}^{1}>0$ as (15) shows.

Finally, the response of today's real exchange to the temporary increase in current government spending on non-tradeables is easy to determine. To begin with, suppose that the domestic aggregate price index, $\Phi^{1}$, is some homogeneous function of degree one in the domestic nominal prices of the imported good and the non-traded good. If this was the case, one could write the current domestic aggregate price level as

$$
\Phi^{1}=P^{1} f\left(p_{N}^{1}\right)
$$

Using the law of one price, it then follows that

$$
\Phi^{1}=\bar{e} P_{F}^{1} f\left(p_{N}^{1}\right)
$$

Now, as is commonly done to get a measure of the real exchange rate, divide the domestic aggregate price index by $\bar{e} \Phi_{F}{ }^{1}$, where $\Phi_{F}{ }^{1}$ is the foreign aggregate price index in the current period. Thus, the measure being used to reflect the real exchange 
TABLE 1

\begin{tabular}{|c|c|c|c|c|}
\hline \multirow[b]{2}{*}{ Disturbances } & \multicolumn{2}{|c|}{$\begin{array}{l}\text { Relative price } \\
\text { of non-traded } \\
\text { goods }\end{array}$} & \multirow{2}{*}{$\frac{\begin{array}{l}\text { Trade } \\
\text { balance }\end{array}}{\hat{t}^{1}}$} & \multirow{2}{*}{$\begin{array}{l}\text { Balance of } \\
\text { payments }\end{array}$} \\
\hline & $\hat{p}_{N}{ }^{1}$ & $\hat{p}_{N}^{2}$ & & \\
\hline \multicolumn{5}{|l|}{ Terms of trade } \\
\hline$\hat{p}_{X}{ }^{1}>0, \hat{p}_{X}{ }^{2}=0$ & + & + & + & + \\
\hline$\hat{p}_{X}^{1}=0, \hat{p}_{X}^{2}>0$ & + & + & - & + \\
\hline$\hat{p}_{X}^{1}=\hat{p}_{X}^{2}>0$ & + & + & $0^{a}$ & + \\
\hline \multicolumn{5}{|c|}{ Government spending on imports } \\
\hline$\hat{g}_{Z}^{1}>0, \hat{g}_{Z}^{2}=0$ & - & - & - & - \\
\hline$\hat{g}_{Z}{ }^{1}=0, \hat{g}_{Z}^{2}>0$ & - & - & + & - \\
\hline$\hat{g}_{Z}^{1}=\hat{g}_{Z}^{2}>0$ & - & - & $0^{a}$ & - \\
\hline \multicolumn{5}{|c|}{ Government spending on non-traded goods } \\
\hline$\hat{g}_{N}{ }^{1}>0, \hat{g}_{N}^{2}=0$ & + & $?^{b}$ & $?^{c}$ & + \\
\hline$\hat{g}_{N}{ }^{1}=0, \hat{g}_{N}^{2}>0$ & $?^{d}$ & + & $?^{e}$ & $?^{d}$ \\
\hline$\hat{g}_{N}{ }^{1}=\hat{g}_{N}^{2}>0$ & + & + & $0^{a}$ & + \\
\hline
\end{tabular}

${ }^{a}$ The following initial conditions have been assumed in deriving this result: $\beta=1 /\left(1+r^{*}\right), \bar{N}^{1}=\bar{N}^{2}, g_{N}{ }^{1}=$ $g_{N}{ }^{2}, g_{Z}{ }^{1}=g_{Z}{ }^{2}, p_{X}{ }^{1}=p_{X}{ }^{2}, \bar{X}^{1}=\bar{X}^{2}$ and $v(\cdot)=v(\cdot 2)$. These initial conditions make the first and second periods identical from the representative agent's perspective.

${ }^{b}$ As mentioned in the text, the sign of this effect depends positively on the sign of $U_{12}\left(N^{1}, Z^{1}\right)$.

${ }^{c}$ As mentioned in the text, the sign of this effect depends positively on the sign of $U_{12}\left(N^{1}, Z^{1}\right)$.

${ }^{d}$ Depends positively on the sign of $U_{12}\left(N^{2}, Z^{2}\right)$

${ }^{e}$ Depends negatively on the sign of $U_{12}\left(N^{2}, Z^{2}\right)$

rate is $\Phi^{1} / \bar{e} \Phi_{F}{ }^{1}=P_{F}{ }^{1} f\left(p_{N}{ }^{1}\right) / \Phi_{F}{ }^{1}$. Note that all foreign prices, and consequently the foreign aggregate price level, $\Phi_{F}{ }^{1}$, are unaffected by any shocks emanating within the domestic economy, since by assumption the domestic economy is a small open one. Therefore, any domestic shocks which lead to a change in the relative price of non-traded goods, $p_{N}{ }^{1}$, will cause a movement in today's real exchange rate. To be specific, in this circumstance

$$
\left.\widehat{\left(\Phi^{1} / \bar{e} \Phi_{F}^{1}\right.}\right)=\left[f^{\prime}\left(p_{N}^{1}\right) / f\left(p_{N}^{1}\right)\right] \hat{p}_{N}^{1} \text {. }
$$

Thus, a temporary increase in current government spending on non-traded goods will cause the real exchange rate, $\Phi^{1} / \bar{e} \Phi_{F}^{1}$, to appreciate, since the relative price of current non-traded goods rises, because $\hat{p}_{N}{ }^{1}$ is positive, as (15) shows.

In concluding this section, table 1 is presented, summarizing some of the main conclusions that can be drawn from the model. It shows the effects that various exogenous disturbances have on the relative price of non-traded goods, the trade balance, and the balance of payments. The line of argument needed to prove those comparative statics exercises not discussed above exactly mimics that employed in analysing the two exercises discussed. ${ }^{15}$ An important point to note from this table is that the correlation between movements in the trade balance and either the relative

15 A full explanation and deviation of all the results shown in table 1 is contained in Greenwood (1983b). 
price of non-traded goods or the balance of payments is ambiguous. This is because the pattern of co-movement between these three variables depends essentially on the nature of the exogenous shock impinging on the system. As can be seen, when analysing the impact of shift in an exogenous variable it is important to distinguish whether the movement in it is transitory or permanent in character and whether it reflects a current unanticipated event or an expected future one. ${ }^{16}$ Finally, note that when taken in isolation the trade balance may be a meaningless economic statistic. This is because theoretically the correlation between movements in the trade balance and economic welfare is ambiguous. For instance, both a temporary improvement in the current terms of trade and an anticipated increase in the future terms of trade lead to an improvement in economic welfare. ${ }^{17}$ As can be seen from table 1 , however, the former generates a tendency towards a trade balance surplus while the latter causes an inclination towards a deficit.

\section{O N C L US I O N S}

A small-scale micro-economic-oriented general equilibrium model is constructed in this paper to explain the joint behaviour of the trade balance, the balance of payments, and the relative price of non-traded goods. The model yields a set of predictions about the relationship between movements in these three variables and certain exogenous variables, such as the terms of trade and government spending. The inclusion of a non-traded good sector into the line of choice-theoretic intertemporal general equilibrium models used recently in international finance is interesting for several reasons. First, disturbances within the non-traded goods sector have implications for the traded goods sector and for variables of interest, such as the trade balance and the balance of payments. Second, shocks occurring outside the non-traded sector will now have additional channel of effect on the open sector of the economy via their impact on the non-traded goods sector. This interconnectedness between the non-traded and traded goods sectors would be more emphasized in a model with endogenous output determination. To do this would be a fruitful extension of the model presented in the paper. In such a model, changes in the relative price of non-traded goods would affect resource allocation between the two sectors and therefore have implications for the productions of non-traded and traded goods. Last, an essential ingredient in any meaningful discussion of the real exchange rate is an analysis of the relative price of non-traded goods.

\section{A P P E N D I X}

It is easy to see from the consumer's problem and the various equilibrium conditions in the model that the following five equations completely characterize the

16 Kimbrough (1983) also notes that it is important to distinguish between permanent and transitory movements in government expenditure; he too breaks down total government expenditure into spending on traded and non-traded goods.

17 Specifically, the change in welfare in the first case is $d \omega=[1-v(\cdot 1)] p_{X}{ }^{1} \bar{X}^{1} \hat{p}_{X}{ }^{1}$, while for the second case it is given by equation (11) in the text. 
determination of $p_{N}{ }^{1}, p_{N}{ }^{2}, Z^{1}, Z^{2}$, and $\lambda$ in the model's general equilibrium; $\lambda$ is the Lagrange multiplier associated with the agent's constrained maximization problem.

$$
\begin{aligned}
& U_{1}\left([1-v(\cdot 1)] \bar{N}^{1}-g_{N}{ }^{1}, Z^{1}\right)=\lambda p_{N}{ }^{1} \\
& U_{2}\left([1-v(\cdot 1)] \bar{N}^{1}-g_{N}{ }^{1}, Z^{1}\right)=\lambda \\
& \beta U_{1}\left([1-v(\cdot 2)] \bar{N}^{2}-g_{N}{ }^{2}, Z^{2}\right)=\lambda p_{N}{ }^{2} /\left(1+r^{*}\right) \\
& \beta U_{2}\left([1-v(\cdot 2)] \bar{N}^{2}-g_{N}{ }^{2}, Z^{2}\right)=\lambda /\left(1+r^{*}\right) \\
& Z^{1}+g_{Z}{ }^{1}+\left[1 /\left(1+r^{*}\right)\right]\left(Z^{2}+g_{Z}^{2}\right)=(1-v(\cdot 1)) p_{X}{ }^{1} \bar{X}^{1} \\
& \quad+\left[1 /\left(1+r^{*}\right)\right][1-v(\cdot 2)] p_{X}{ }^{2} \bar{X}^{2}
\end{aligned}
$$

Now, how will an anticipated gain in the future terms of trade, $p_{X}{ }^{2}$, affect today's consumption of imports, $Z^{1}$, and consequently today's trade balance, $t^{1}$ ? The answer to this equation is easily obtained by subjecting equations (A2), (A4), (A5) and (9) to the usual sort of comparative statics exercise. The results of this exercise are

$$
\begin{aligned}
\partial Z^{1} / \partial p_{X}{ }^{2}=\left\{\left(1+r^{*}\right) \beta U_{22}(\cdot 2) /\left[U_{22}(\cdot 1)+\beta\left(1+r^{*}\right)^{2} U_{22}(\cdot 2)\right]\right\} \\
\cdot[1-v(\cdot 2)] \bar{X}^{2}>0
\end{aligned}
$$

and

$$
\partial t^{1} / \partial p_{X}^{2}=-\left(\partial Z^{1} / \partial p_{X}^{2}\right)<0 .
$$

Consequently, the solution for $\hat{t}^{1}$, as given by equation (14) in the text, is unambiguously negative as was stated.

Next, equations (A1), (A2), and the above solution for $\partial Z^{1} / \partial p_{X}{ }^{2}$ can be used to see how $p_{N}{ }^{1}$ is affected by a shift in $p_{X}{ }^{2}$. One finds that

$$
\partial p_{N}{ }^{1} / \partial p_{X}{ }^{2}=-\left[\left(p_{N}{ }^{1} U_{22}(\cdot 1)-U_{12}(\cdot 1)\right) / U_{2}(\cdot)\right]\left(\partial Z^{1} / \partial p_{X}{ }^{2}>0\right.
$$

(recall that $\partial Z^{1} / \partial p_{X}^{2}>0$ ), where the above expression is unambiguously positive, owing to the assumption that first-period non-traded goods are normal, which implies that $\left[p_{N}{ }^{1} U_{22}(\cdot 1)-U_{12}(\cdot 1)\right]<0$. An immediate implication of the above result is that the solution for $\hat{p}_{N}{ }^{1}$ in this case, as given by (12) in the text, must also be unambiguously positive. Since all the terms in the numerator of (12) are positive, it must therefore follow that (12)'s denominator, or $\Delta$, is positive also. It is easy to show in a similar fashion that $\partial p_{N}{ }^{2} / \partial p_{X}{ }^{2}>0$.

The effect on today's consumption of imports, $Z^{1}$, of a temporary shift in current government spending on non-traded goods, $g_{N}{ }^{1}$, will be investigated now. This effect can be uncovered through the use of (A2), (A4), and (A5). One finds that

$$
\partial Z^{1} / \partial g_{N}{ }^{1}=U_{21}(\cdot 1) /\left[U_{22}(\cdot 1)+\beta\left(1+r^{*}\right)^{2} U_{22}(\cdot 2)\right] \stackrel{?}{\gtrless} 0
$$

and, thereby, through (9) that

$$
\partial t^{1} / \partial g_{N}{ }^{1}=-\left(\partial Z^{1} / \partial g_{N}^{1}\right) \stackrel{?}{\gtrless} 0
$$


Therefore, $\partial Z^{1} / \partial g_{N}{ }^{1} \gtreqless 0$ iff $U_{21}(\cdot 1) \lesseqgtr 0$, while $\partial t^{1} / \partial g_{N}{ }^{1} \gtreqless 0$ iff $U_{21}(\cdot 1) \gtreqless 0$. Thus, the sign of $\hat{t}^{1}$, which is shown by equation (17) in the text, depends positively on the sign of $U_{21}(\cdot 1)$ as was mentioned.

How does the temporary increase in $g_{N}{ }^{1}$ affect $p_{N}{ }^{2}$ ? By undertaking the required comparative statics exercise on equations (A3), (A4), and (A5), it can be seen that

$$
\partial p_{N}{ }^{2} / \partial g_{N}{ }^{1}=\left\{\left[p_{N}{ }^{2} U_{22}(\cdot 2)-U_{21}(\cdot 2)\right] / U_{2}(\cdot 2)\right\}\left(1+r^{*}\right)\left(\partial Z^{1} / \partial g_{N}{ }^{1}\right) \stackrel{?}{\gtreqless} 0
$$

Thus, $\partial p_{N}{ }^{2} / \partial g_{N}{ }^{2} \gtreqless 0$ as $U_{21}(\cdot 1) \gtreqless 0$. This implies that expression (16) in the text describing $\hat{p}_{N}^{2}$ in this situation must be positively related to the sign of $U_{12}(\cdot 1)$. (Note that because second-period non-traded goods are normal goods $\left[p_{N}{ }^{2} U_{22}(\cdot 2)-\right.$ $\left.U_{21}(\cdot 2)\right]<0$.)

Finally, how would $p_{N}{ }^{1}$ respond to this change in $g_{N}{ }^{1}$ ? Equations (A1), (A4), (A5), and (A7) provide the answer to this question. One finds that

$$
\begin{aligned}
& \frac{\partial p_{N}{ }^{1}}{\partial g_{N}{ }^{1}}= \\
- & \frac{\left\{\left[U_{11}(\cdot 1) U_{22}(\cdot 1)-U_{12}{ }^{2}(\cdot 1)\right]+\beta\left(1+r^{*}\right)^{2} U_{22}(\cdot 2)\left[U_{11}(\cdot 1)-p_{N}{ }^{1} U_{21}(\cdot 1)\right]\right\}}{\beta\left(1+r^{*}\right)\left[U_{22}(\cdot 1)+\beta\left(1+r^{*}\right)^{2} U_{22}(\cdot 2)\right] U_{2}(\cdot 2)}>0 .
\end{aligned}
$$

The above solution for $\partial p_{N}{ }^{1} / \partial g_{N}{ }^{1}$ is unambiguously positive in sign. (Recall that $\left[U_{11}(\cdot 1)-p_{N}{ }^{1} U_{21}(\cdot 1)\right]<0$, since first-period imported goods are normal goods.) Consequently, the expression for $\hat{p}_{N}{ }^{1}$ in this circumstance, as given by (15) in the text, must also be unambiguously positive.

\section{REFERENCES}

Aschauer, David and Jeremy Greenwood (1983) 'A further exploration in the theory of exchange rate regimes.' Journal of Political Economy 91, 868-75

Dornbusch, Rudiger and Jacob Frenkel (1973) 'Inflation and growth: alternative approaches.' Journal of Money, Credit and Banking 5, Part I, 141-56

Greenwood, Jeremy (1983a) 'Expectations, the exchange rate and the current account.' Journal of Monetary Economics 12, 543-69

- (1983b) 'Relative prices, the trade balance, and the balance of payments.' Research Report No. 8306, Department of Economics, University of Western Ontario, January

Helpman, Elhanan (1981) 'An exploration in the theory of exchange rate regimes.' Journal of Political Economy 89, 865-90

$\rightarrow$ Jones, Ronald W. (1974) 'Trade with non-traded goods: the anatomy of interconnected markets.' Economica, 41, 121-38

Kimbrough, Kent P. (1983) 'An examination of the effects of government purchases in an open economy.' Journal of International Money and Finance, forthcoming

$\rightarrow$ Lucas, Robert E. (1982) 'Interest rates and currency prices in a two-country world.' Journal of Monetary Economics 10, 335-60

Obstfeld, Maurice (1981) 'Macroeconomic policy, exchange-rate dynamics and optimal asset accumulation.' Journal of Political Economy 89, 1142-61

- (1982) 'The capitalization of income streams and the effects of open-market policy under fixed exchange rates.' Journal of Monetary Economics 9, 87-98 
Persson, Torsten (1984) 'Real transfers in fixed exchange rate systems and the international adjustment mechanism.' Journal of Monetary Economics 13, 349-69

Sachs, Jeffrey (1983) 'Aspects of the Current Account Behavior of OECD Economies,' In Emile M. Claassen and Pascal Salin, eds, Recent Issues in the Theory of Flexible Exchange Rates (New York: North-Holland)

Stockman, Alan C. (1980) 'A theory of exchange rate determination.' Journal of Political Economy 88, 673-98

- (1981) 'Effects of inflation on the pattern on international trade and payments.' NBER Working Paper Series No. 713, October

$\rightarrow-(1983)$ 'Real exchange rates under alternative nominal exchange rate systems.' Journal of International Money and Finance 2, 147-66 